\title{
Research on Various Building Materials for Structural Components
}

\author{
Wei Wu \\ The Department of Architecture and Engineering Qinhuangdao College, Northeast Petroleum University, \\ Qinhuangdao, 066004, China
}

\begin{abstract}
This paper firstly introduces the characteristics of several kinds of building materials. Based on them, several structural components includes concrete structure, steel structure, Steel concrete hybrid structure are produced. Structural characteristics and application in practical projects of these components are described. Besides this, the technology problems needed to pay attention in architectural design are also analyzed.
\end{abstract}

Keywords-building material, structure member, engineering application

\section{INTRODUCTION}

Building materials can be divided into structural materials, decoration materials and some special material. Structural materials including wood, bamboo, stone, cement, concrete, metal, glass, ceramic tile, engineering plastics, composite materials; decorative materials include a variety of coatings, paints, coatings, veneer, colored tiles, glass with special effects, etc.; special material for waterproof, moisture-proof, anti-corrosion means, fire prevention, flame retardant, sound insulation, sealing, etc.. According to the properties of building materials can be divided into inorganic material, organic material and composite material. Inorganic materials turn into metal and nonmetal materials. Organic materials are natural; also have artificial synthesis[1].

According to the effect of different materials in the building, building materials can be divided into two categories: the first category is the load-bearing structure uses material, such as brick, stone, concrete, mortar, steel and wood, etc. The second category is the special materials, such as sound absorption board, refractory brick, antirust paint, foam glass, color cement etc. Construction material is the basis of building engineering. It determines the building strong, durable, applicable, economic and beautiful[2].

The general structural member refers to bear the load, the load transfer components, such as bearing wall, column, beam, foundation, and so on; filled wall, the other window, door and so on which belongs to building component wall, plate, beam, column, stair, belong to the component, component is the pouring of concrete in building houses part of collectively[3].

\section{THE REINFORCED CONCRETE MEMBER}

Concrete properties of concrete and steel thermal expansion coefficient are almost the same, which can ensure the two materials combine to produce synchronous thermal deformation together. Therefore, the reinforced concrete structure is an important characteristic of environmental temperature changes will only cause the interface to the strain is small in the reinforced concrete member. The compressive strength of concrete is large but the tensile strength is smaller, by plane pure shear, concrete principal tensile stress and shear and forms a 45 degree angle, and the principal stress and the principal tensile stress of orthogonal.

The main stress value "shall be calculated from the Mohr stress circle", and as long as the concrete not cracking and maintain elasticity, principal tensile shear value and role stress for the same. When the principal tensile stress reaches its tensile strength, concrete cracking, then the shear stress reaches the tensile strength of the concrete, that is to say, the concrete shear strength and tensile strength of the same.

\section{STEEL MATERIAL COMPONENT}

Steel structural features from the British Industrial Revolution period, the iron and steel have been applied to build bridges and buildings in. A famous case is the London Expo built the Crystal Palace and the Paris World Expo the construction of the Eiffel Tower. By Eiffel design Statue of Liberty in New York is a steel structure. Now, steel has been widely used in high-rise buildings, large-span stadium roof steel factory, industrial building, the school gym, supermarkets and large warehouse.

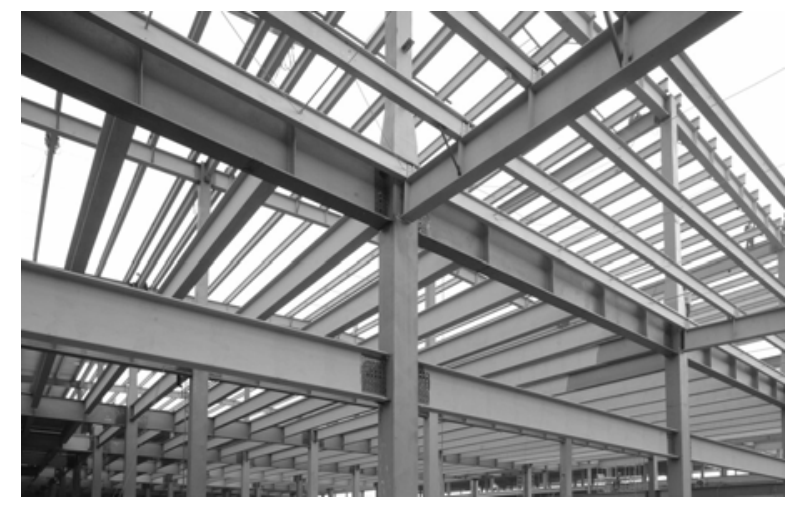

Fig.1: Steel structure diagram

Recent data indicate that the total construction area of wood, steel structure building in Japan's slightly big, steel structure is a structure is widely used in Japan. Compared with the steel structure and concrete structure has the following advantages: steel structure weight is much smaller than the concrete structure, which can reduce the 
workload of steel structure member basis; usually manufactured in a factory, and then transported to the site and assembled by welding structure of high strength bolt. Steel structure construction period is much shorter than the concrete structure and the space more flexibility allowed in the architectural design, as shown in Fig.1.

\section{THE MATERIAL OF STEEL REINFORCED CONCRETE MIXED STRUCTURE}

High-rise building American characteristics of steel reinforced concrete structure of the traditional brick and stone building in the European architectural style at the beginning of construction. However, as the height of the building increases, the brick masonry structure can no longer support its own weight. Therefore, the steel is embedded brick pillars to provide extra strength.

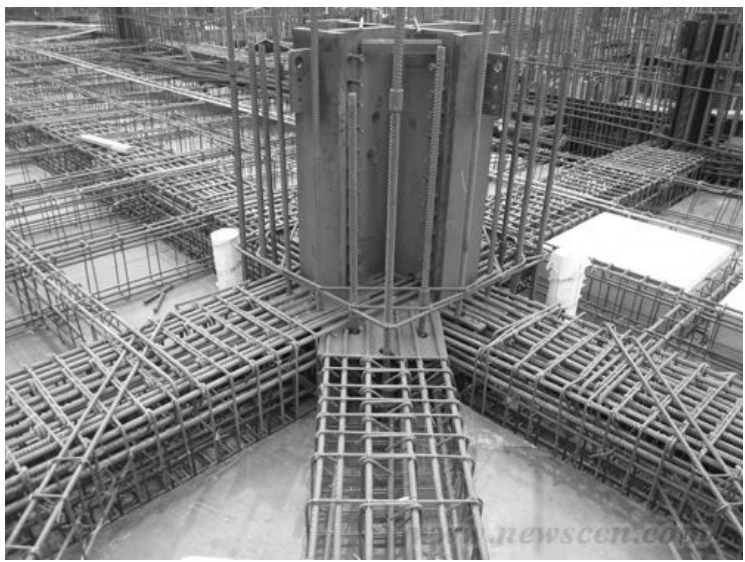

Fig. 2: Steel concrete hybrid structure

In twentieth Century 30 in New York and Chicago in the high-rise building, steel is assumed almost the entire load, and the brick and concrete block used only to increase the construction rigidity and provide fire protection for steel. Early Japanese built using construction method, the same since then, steel and concrete composite structure formed by the steel column and steel beam embedded in reinforced concrete began to be incorporated into the design considerations. This kind of structure system using the first built in 1923 in Japan in May the Industrial Bank of Japan office building, built after a few months, the building was experienced in 1923 great Kanto earthquake in Japan in September, and survive and almost not damaged. In encouraging this successful case, Japan began to SRC structure is widely used in building height less than $60 \mathrm{~m}$. This kind of structure system to avoid their disadvantages in the use of reinforced concrete structure and steel structure advantages at the same time, as shown in Fig.2.

As mentioned above, steel structure has the advantages of easy yielding, buckling and fire resistance is poor shortcomings, can pass through the steel member embedded in the concrete to make up; at the same time, brittle shear in the role of higher axial force under the reinforced concrete column failure can be avoid by embedding the steel member; usually by its own weight limit of the traditional reinforced concrete beam span can also be increased by embedding steel member.

\section{PlastiC DEFORMATION BEHAVIOR AND STRENGTH STRUCTURE}

The prospect of above of ultra high strength steel has been discussed characteristics of wood structure, reinforced concrete structure, steel structure and steel reinforced concrete structure. In Japan, American west coast, Chinese, Philippines, Italy, and Turkey, Algeria, Iran and India are the earthquake occurred. In all regions, the seismic design of building structures is an unavoidable social problem, as discussed above, suggestions, plastic deformation is crucial to the performance of whether it can survive in the earthquake in the structure.

In retrospect, the beginning of the twenty-first Century, the development of structural materials has made great contribution to the development of human history and civilization, and ultra high strength steel not only has higher strength, but also has satisfactory scalability and durability, is expected in the future development of architectures will play an important role. With the increase of the strength of steel, required for the construction of the same building to reduce the weight of steel, the weight of the structure is reduced and smaller structure member. In other words, the structural component of the same size, the use of highstrength material structure can be built larger.

\section{FROM THE BUILDING TO CITY OF SEISMIC ELASTIC}

\section{A. The seismic performance of city}

Structure according to the seismic fortification from high to low, there is isolation structure, structural passive control, seismic structure based on the strength and ductility of structure. In the highly developed technology today, as long as the future characteristics and intensity of earthquakes does not exceed the expected design, believe that the above four types of seismic structures will show the expected performance.

In the face of nature, structural engineers should not be proud of technology. Because the Japanese Kobe earthquake in 1995, announced after a many beat all problems of seismic ductility performance of the overall structure, and these ductile structures before Japan Kobe earthquake was considered to be the most reliable structure, but the structure even in the earthquake does not collapse, after the earthquake will not be restored because of excessive deformation, the structure of the seismic performance and can not meet the needs of the society. Earthquake is a natural phenomenon, building structure seismic design problem is the most difficult to predict any little, about the size of future earthquakes and occurrence 
time forecast is not reliable. Earthquake occurrence probability is low, does not represent not happen.

Seismic design, because of the need to balance the seismic safety and construction economy, generally do not consider such large earthquakes, but the city safety is concerned, it is more like and the nature of gambling. The single building life of only about 60 years, and composed of a large number of single building of the city, there may be hundreds or even thousands of years. The seismic intensity of earthquake resistance of building design and construction can resist is determined according to the single building life, seems insufficient to ensure the service life is longer than the single building of the whole city safety. On the other hand, if the design of the building to withstand the maximum earthquake may happen in the future, but such a large building in decades of life in the earthquake did not occur, but also the waste of money and resources, it does existed contradictions.

\section{B. The beauty of life and meaning of building structure}

Buildings generally parallel with food and clothing, to provide space for human activities, from wind and rain hit, and ensure the safety of human life in the earthquake. In fact, these are just the minimum requirements for the construction, but not just satisfied with this. Because the construction in the shelter as humans also created a history and culture, the building is human activity, including places of cultural activities, 2004 Chicago center completed the open-air music hall Millennium Park Music pavilion. Communication pipeline as extending from a stage is a giant ribbon Christmas gift, the band on stage to the audience the dissemination of music sitting on the grass by the pipeline. The pipe support structure of speaker, not only have to bear the weight of the speaker, also need to be able to withstand the strong winds of Chicago. To build such a seemingly simple structure, the use of new materials and advanced design, manufacture and construction process is very necessary, desire it also remind us to have been doing something new.

\section{CONCLUSIONS}

The main bearing member of this kind of buildings with brick, brick wood structure made of wood. The vertical components such as a wall, column with brick, wood made of horizontal load-bearing component of floor, roof etc. This structure houses fewer layers, and more for the single storey building. Brick concrete structure buildings with brick masonry wall, column, beam, floor, roof, stairs with reinforced concrete production, become brick and reinforced concrete structure. The structure of multi layers in civil buildings and small industrial plants is a widely used structure form. Structure: reinforced concrete buildings, floor, beam, column base with all the reinforced concrete production. Frame beam, slab, column, foundation form a load-bearing, so also called frame structure. The wall only plays the role of enclosure, brick. Load-bearing structures of buildings with steel, wall made of bricks or other materials.

\section{REFERENCES}

[1] Li, S. The use of green building materials and create a healthy living environment. Reform and Opening Up, 22(10), pp.120-121, 2010.

[2] Zhuang, J. Y. Building energy-saving and energy-saving building materials. Wall Materials Innovation and Building Energy Saving, 7(8), pp.47-49, 2005.

[3] Zhang, J. H. On the ecological construction and ecological building materials. Shanxi Building, 12(7), pp.89-90, 2002. 